\title{
COMPUTER BEATS GRANDMASTER
}

\author{
David Levy \\ London, England
}

For the sake of future historians I believe that it is necessary to be precise about the significance of the win by DEEP THOUGHT 0.02 against Bent Larsen in the Software Toolworks tournament in November. This was not the first time that an International Grandmaster had lost a game of chess against a computer program. In fact this occured in blitz (5-minute) games more than a decade ago, with Michael Stean and Robert Hübner being the first victims. Nor was this the first occasion on which a holder of the title of International Grandmaster had been defeated by a computer under "tournament conditions", i.e. with a rate of play of 40 moves in 2 hours or thereabouts. That particular trophy went to HITECH for its victory (in three games) against Arnold Denker of the USA by $31 / 2-1 / 2$. But with all due respect to Denker, he was 73 years of age at the time of the match. Futhermore his GM title was awarded by FIDE quite recently because of his long and illustrious chess career - he had not actually achieved the performance norms required under the title regulations. DEEP THOUGHT's win against Bent Larsen is the first time in history that a computer program has won under tournament conditions against a human player who has qualified for the title of International Grandmaster. This pedantic definition goes part of the way towards explaining the great significance of the program's achievement, but more explanation may be necessary for readers who have little or no knowledge of the world of human chess. Bent Larsen is not merely a Grandmaster, he is one of the most successful competitive players since the war. He was awarded the Grandmaster title in 1956 and he still competes regularly in top level events. In addition to a long string of first prizes in major international tournaments, Larsen once achieved the distinction of winning five consecutive major tournaments, including an Interzonal qualifying competition in the World Championship cycle. In 1970 he played first board for the Rest-of-the-World Team, ahead of Bobby Fischer, in the Match of the Century against the U.S.S.R., in which he scored 50\% (1 win, 1 draw, 1 loss) against the reigning World Champion Boris Spassky.

Larsen's best 5-years average Elo rating ${ }^{1)}$ is 2640, and he is currently (Jan 1989) rated 2550 on the ELO list (equivalent to approximately 2680 in the USCF). To put the Larsen $v s$. DEEP THOUGHT and Denker $v s$. HITECH encounters into perspective, it is necessary to mention that Denker's ELO rating at the time of their match was 2300, and that Larsen's age is 53.

Only a few weeks after losing this milestone encounter, Bent Larsen graciously agreed to an interview with the ICCA Journal. The interview was conducted by David Levy on January $8^{\text {th }} 1989$, during a rest day at the annual Hastings International tournament where Larsen was competing.

ICCA: Around ten years ago, whenever I would say to a Grandmaster that in his lifetime there would be a chess program stronger than he, the Grandmaster would always laugh at me. When was the first time that you thought it possible that you could lose to a computer program?

LARSEN: I still don't think that is possible! What happened to me in Long Beach was that I got very angry when I had to play the machine. And then I got even more angry when I was told that I could have signed a note saying that I did not want to be paired against it. I did not know that.

ICCA: Why would you prefer not to play against computers?

1) When referring to Elo ratings I mean the rating scale adopted by FIDE. The U.S. Chess Federation employs essentially the same system and a similar scale, but USCF ratings are usually 100 points or more above the corresponding Elo rating figures. 
LARSEN: I play very few tournaments and when I come there I come to play Miles and Browne and Tal. I don't come to play a stupid machine. In general I don't like to play machines in tournaments. If they want to play with me we can play in laboratories.

ICCA: What did you think about the play of the program during the game?

LARSEN: I was not impressed at all. I thought it was rather ridiculous. For instance, there is a point where it protects the Pawn on c6. It has a weak Pawn on c6 and it plays a clumsy rook move, ... Re6 I think it is, to protect the Pawn. But it is a Pawn I cannot take, so I don't understand why it protects it.

ICCA: Did you feel in any way psychologically intimidated during the game?

LARSEN: I felt intimidated before the game that I had to play this machine. I felt very uncomfortable. We were placed in the faraway corner of a big hall exactly at the place where the cold air was blown into the hall. I was very annoyed.

ICCA: What did the other Grandmasters think about the play of DEEP THOUGHT in general? Where they impressed?

LARSEN: In such a tournament, where in four days you play eight rounds and before you know it the tournament is over, people have no time to talk, and I don't think there was much talk about it. I remember Browne's wife saying something about the computer. She was very nervous about it, and Walter would not sign this list you know, not to play it. But that is about the only thing I discussed with anybody there about it.

ICCA: Grandmaster Ulf Andersson said a few months ago that he is very much against the idea of computers playing in human tournaments. He thinks that computers should play with computers and humans with humans. What is your feeling about this in general?

LARSEN: Tournaments shouls be what tournaments have always been. If you sit down to develop a computer you do that in a laboratory. So I definitely agree with Ulf.

ICCA: Walter Browne was the only player in the tournament who beat DEEP THOUGHT. Did he do anything special? Did he change his style in any way?

LARSEN: I don't know if he changed his style. I know that he sacrificed the exchange to create a complex position. He had said that the weakness of this computer was in tactics. He had seen some of its other games.

ICCA: That is interesting, because most people believe that tactics are the computers' strong point.

LARSEN: Yes, but that is in tactics of a very few moves.

ICCA: If you had to play against DEEP THOUGHT again in a tournament or a match, would you change your style at all?

LARSEN: No, I would just play well. In the game I had a very strong position and I made one very bad move, that was my King getting in the way of my Bishop's retreat, and after that it was not so easy. When I tried the combination I more or less knew it was wrong. But I was just very annoyed.

ICCA: Berliner's program HITECH has discovered some innovations in the opening by examining some of the assessments and positions in the Informator Encyclopaedia, looking for new moves and tactical ideas that the analysts have missed. Do you think that in the future Grandmasters will use computers to help them prepare opening innovations? 
LARSEN: Yes, I read that in the publicity for the computers, but to find mistakes in the Encyclopaedia is not difficult. But for myself I can say I have no plans to use them because I think they will be too slow. I think it is a very slow way of finding ideas in the opening. But maybe.

ICCA: What about adjourned games? Do you think it will be long before Grandmasters regularly use computers to help them analyze adjourned games?

LARSEN: Well, if it is an adjourned game for instance like the one the machine got in Long Beach, it got Rook and Bishop against Rook. Things like that, yes. Then that will happen. The computer got that against Fishbein. They say he made a blunder on his sealed move.

ICCA: But what about adjourned games in general? You could have a computer thinking all night while you were sleeping, and then you could look at its analysis in the morning. Do you think this is likely to happen in Grandmaster chess?

LARSEN: I don't know. In such technical endings, yes. It's also known that they have Queen against Rook in some programs. In general I would not like to rely on it, but neither would I like to rely on a "second".

ICCA: What about these databases? You mentioned Queen against Rook which is a good example. Are you impressed with what the computers have done?

LARSEN: I like the thing with the two Bishops against the Knight. That is what has impressed me most.

ICCA: And in Rook and Bishop against Rook they have found that some positions are winnable but in more than 50 moves.

LARSEN: That was already suspected. But I must say that with two Bishops against Knight it has been known for a long time that theory was not correct. For all that, the winning method is very difficult. When you make these winning moves, the only purpose of which is to get the Bishop as far away from the Knight as possible. That is quite impressive.

ICCA: It seems that already some players are using these databases as teachers, so that they can improve their technique in such endings. Recently, in Thessaloniki, Spassky and Beliavsky tried and failed to win against the database when they had the Queen and the computer had the Rook, but the Polgar sisters had studied this endgame by using the database and they managed it rather easily. Do you think that players of your calibre will use computers in the future to teach them how to play in such positions?

LARSEN: Maybe not for Queen against Rook. It would be nice for the once in your lifetime that you have two Bishops against Knight, but it is too much work.

ICCA: Isn't it too much work to study it by yourself?

LARSEN: Yes, but you hope you never get it.

ICCA: What do you think of the idea of having a team of computers playing in the Olympiad?

LARSEN: That is horrible. It would be a new reason for me not to play in the Olympiad. I think it is ugly.

ICCA: But don't you think the publicity it would bring ....

LARSEN: I think it is a bad kind of publicity.

ICCA: Do you think that computer programs should be eligible for International Master and Grandmaster titles and ratings? 
LARSEN: No, of course not. For many reasons. Firstly, I have said already they should not play tournaments. Secondly, a computer is not defined. A computer does not have a passport or identity card like a human being. These computers are changed all the time.

ICCA: But human beings also get stronger and weaker.

LARSEN: Yes, that's OK but it is still the same human being. It is not the same program. It is not the same machine. You don't know.

ICCA: You have always been one of the most original and creative of Grandmasters. Do you think it is acceptable to use words such as "original", "creative" or "beautiful" when talking about games played by a computer?

LARSEN: Yes. I think the analysis of two Bishops against Knight is beautiful.

ICCA: Some people believe that playing chess will lose its point, have no meaning for humans, when the day comes that a program can beat the human World Champion. Do you hold this view?

LARSEN: No, I don't agree with it. It is like complaining that big machines can do what used to be muscular work better than a man, or better than 100 men. I don't agree that it would take anything out of the game.

ICCA: The first time that a computer played in a tournament with humans was in 1967 and its rating was around 1500 Elo. Now DEEP THOUGHT is around 2400 Elo, and the progress during the last couple of years has been rapid. When do you think they will be better than Kasparov?

LARSEN: I don't know. I don't think it will be in my lifetime. Because they have not done anything new. It is well-known that the two programmers who progressed with this CHESS 3.0 and CHESS 4.5 and so on, it is well-known how they split up because one of them wanted to go on making little improvements and the other one wanted to start from scratch. And I don't think that this way they will get to World Championship strength.

[As an Editorial aside, we translate an extract from a Dutch Computer Journal, Computable, 6 January 1989, p. 25, in which IGM Hans Ree states:]

"What happened to Larsen is bad. Last month, I spoke to him in Mexico at the Active Chess World Championship. I asked him: 'What have you done to us now? Just after I wrote too, that a computer cannot win from a strong chess-player'.

The tall Dane regarded me sadly and solemnly spoke: 'You were perfectly right. The computer indeed cannot win from a strong player'.

I should have liked to know more about it, but Larsen refused to be drawn out any further."

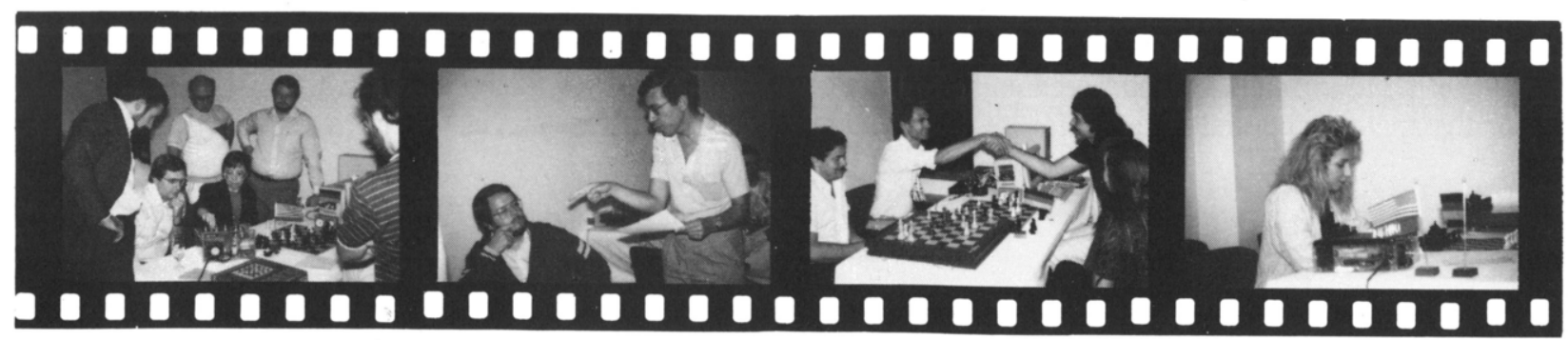

Photo by Frederic Friedel and Dieter Steinwender 